\title{
Technical and economic assessment of wind power potential of Nooriabad, Pakistan
}

\author{
Zahid Hussain Hulio ${ }^{1 *}$, Wei Jiang ${ }^{1}$ and S. Rehman ${ }^{2}$
}

\begin{abstract}
Background: Pakistan is a developing nation and heavily spends on the development of conventional power plants to meet the national energy demand. The objective of this paper is to investigate wind power potential of site using wind speed, wind direction, and other meteorological data collected over a period of 1 year. This type of detailed investigation provides information of wind characteristics of potential sites and helps in selecting suitable wind turbine.

Methods: The site-specific air density, wind shear, wind power density, annual energy yield, and capacity factors have been calculated at 30 and $50 \mathrm{~m}$ above the ground level (AGL). The Weibull parameters have been calculated using empirical (EM), maximum likelihood (MLM), modified maximum likelihood (MMLM), energy pattern (EPFM), and graphical (GM) methods to determine the other dependent parameters. The accuracies of these methods are determined using correlation coefficient $\left(R^{2}\right)$ and root mean square error (RMSE) values. At last, the wind energy economic analysis has been carried out at 30- and 50-m heights.
\end{abstract}

Results: The annual mean wind speeds were found to be 5.233 and $6.55 \mathrm{~m} / \mathrm{s}$ at 30 - and $50-\mathrm{m}$ heights, respectively, with corresponding standard deviations of 2.295 and 2.176. All methods fitted very well with the measured wind speed data except GM model. The frequency of wind speed observed that Weibull distribution gave better fitting results than Rayleigh distribution at wind site. The mean wind power densities were found to be 169.4 and 416. $7 \mathrm{~W} / \mathrm{m}^{2}$ at 30- and 50-m heights. The economic analysis showed that at Nooriabad site in Pakistan, the wind energy can be produced at US\$0.02189/kWh at a hub height of $50 \mathrm{~m}$.

Conclusions: The results showed that the site has potential to install utility wind turbines to generate energy at the lowest cost per kilowatt-hour at height of $50 \mathrm{~m}$.

Keywords: Wind energy, Weibull parameters, Wind shear, Wind power density, Capacity factor, Economic assessment

\section{Background}

Energy resources are important for socio-economic development of a nation. To maintain status quo in terms of socio-economic development, states need economical and consistent supply of energy. Due to fluctuating and always increasing international oil prices, states try to find out alternative, natural, clean, and renewable sources of energy. These sources include but not limited to biogas, biomass, hydro, tidal, thermal, solar photovoltaic, and wind energy.

\footnotetext{
* Correspondence: zahidhussain@163.com

'School of Mechanical Engineering, Dalian University of Technology, Dalian, Liaoning 116024, China

Full list of author information is available at the end of the article
}

The renewable energy sources are environment-friendly and available free of cost, have no political or geographical boundaries, are distributive in nature, and can be tapped anywhere. The Kyoto Protocol paved the way to global community to enhance power generation using new and renewable sources of energy. Of the above mentioned renewable sources of energy, wind and solar photovoltaic have been exploited in many countries and are contributing towards achieving the set goals of clean energy capacities.

In recent years, wind power technology has reached to commercial acceptance and has become economically competent with regular sources of energy. It is easy to 
install and takes a minimal time for its realization compared to other power plants. Continuously encouraging international trends are clear indicative of an increasing role of renewable energy sources in general and wind in particular in meeting the current and future electricity demands. The cumulative annual growth of global wind power installed capacity reached $487 \mathrm{GWh}$ at the end of year 2016, an increase of about 54 GW (12.5\%) compared to 2015, as shown in Fig. 1 [1]. Like previous years, China dominated the wind energy power market with new addition of $23.328 \mathrm{MW}$ in 2016. With new capacity additions of 8.203, 5.443, 3.612, and 2.014 MW, the USA, Germany, India, and Brazil took the 2nd, 3rd, 4th, and 5th place, respectively. Furthermore, France, Turkey, Netherlands, the UK, and Canada took 6th to 10th place with new wind power capacity additions of 1.561, 1.387, 0.887, 0.736, and $0.702 \mathrm{GW}$.

Pakistan is a developing nation and heavily spends on the development of conventional power plants to meet the national electricity demand. The national oil imports have been on rise at $3.8 \%$ per year since 1991 . The total consumption of fossil fuels increased to 67 million tons of oil equivalent (TOE) in 2014 compared to 28.6 million TOE in 1990 [2]. The total natural gas and oil consumption accounted for $72 \%$. In the meantime, the international oil prices increased up from US $\$ 23$ barrel to US $\$ 50.05$ barrel in 2001 . This is almost $115 \%$ rise of oil price in a short span of time. Natural gas is a local abundant source of energy but started to decrease due to increased dependence upon it. The provincial (Baluchistan, KPK, Punjab, and Sindh) production and consumption of natural gas is depicted in Fig. 2a while the annual average increased consumption of gas is compared with oil is given in Fig. $2 b$. The natural gas production is highest in Sindh province while the maximum consumption is seen in Punjab. In other province, the natural gas production is more than consumption as seen in Fig. 2a. The annual consumption of natural gas during 2001 to 2014 is found to be more than oil as shown in Fig. 2b.

Due to energy shortages, the country lost $2 \%$ of the GDP [3]. These power shortages resulted into closure of

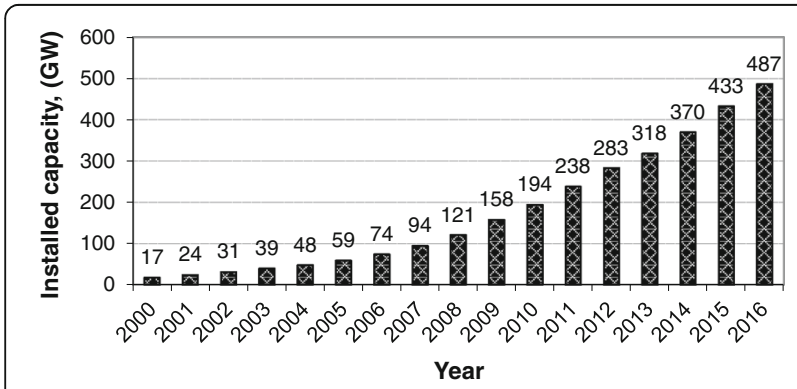

Fig. 1 Global wind power installed capacity

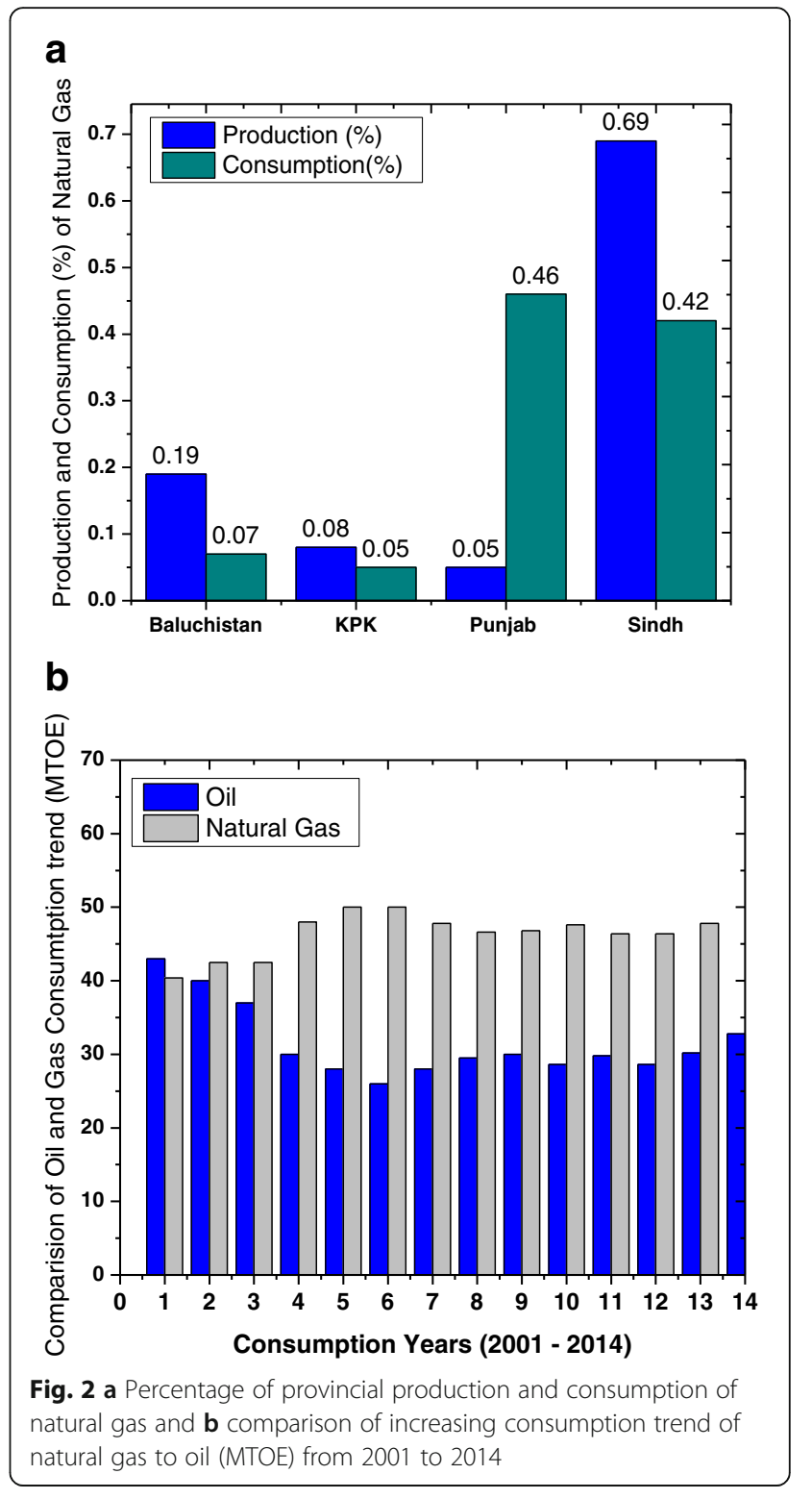

factories, paralyzed industrial production, and exacerbating the unemployment. The national demand of electricity in the country is $18,000 \mathrm{MW}$ whereas the supply is $11,500 \mathrm{MW}$. The supply and demand gap is around $6500 \mathrm{MW}$ [3]. This gap can be compensated to a certain extent by penetrating through renewable sources of energy such as solar and wind. Pakistan has considerable wind potential available in different regions of Sindh and Baluchistan provinces as per findings of the metrological department based on measured wind data. National Renewable Energy Laboratories (NREL) prepared wind maps of the Pakistan, given in Fig. 3. Accordingly, Pakistan has $68,863 \mathrm{~km}^{2}$ appropriate land; about $9.06 \%$ of total land can be used for wind farm development. Sindh and Baluchistan areas have been identified as wind corridors in the country. The coastal belt of Sindh has 


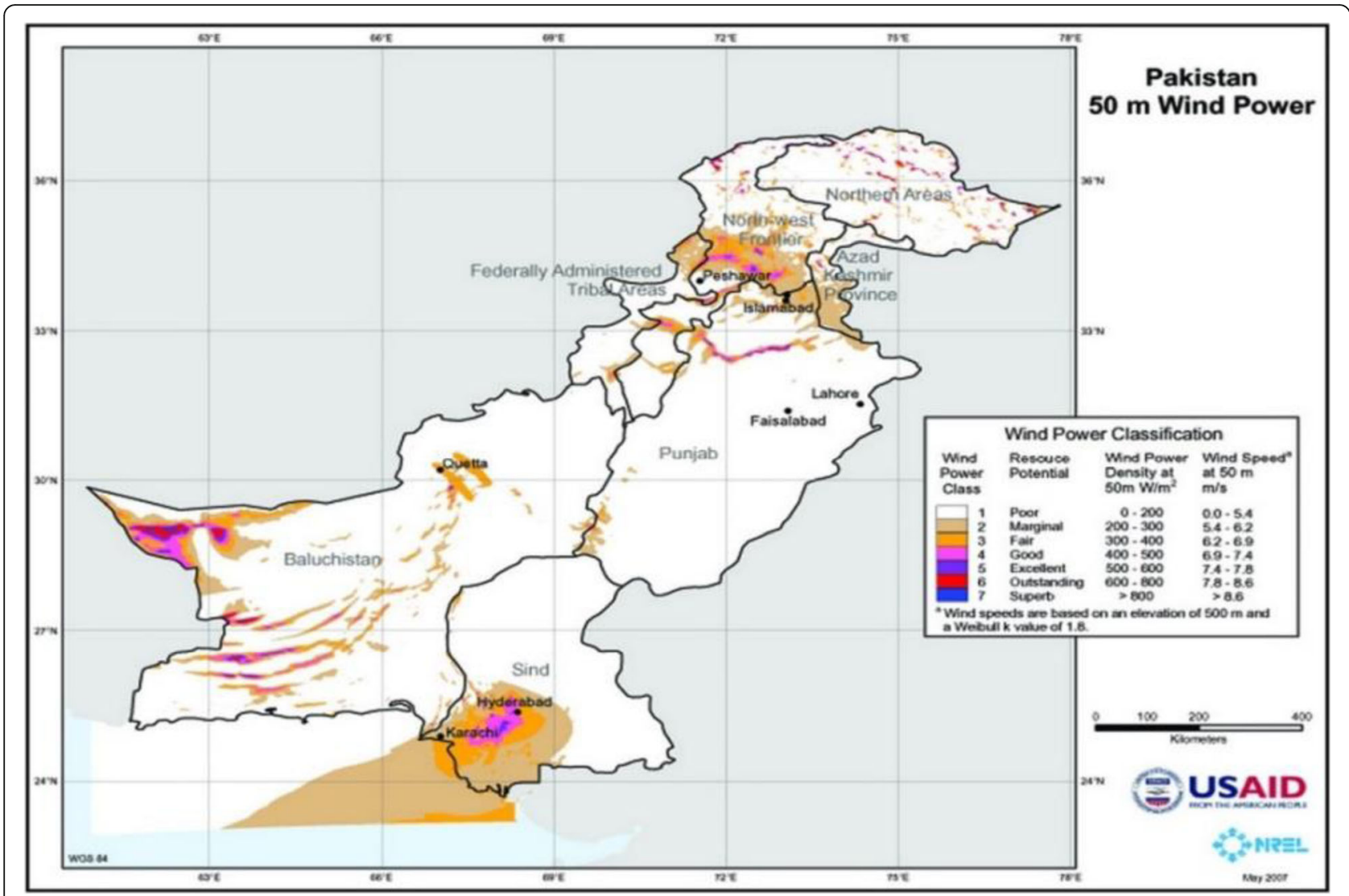

Fig. 3 NREL wind power classification of Pakistan [4]

$2.5 \%$ of land which is favorable for production of wind energy [4].

Till 2003, Pakistan did not have any working power plant based on renewable sources of energy. Later on, due to rising prices of oil and gas, the government established "Alternate Energy Development Board" of Pakistan. The objective of this board was to develop, facilitate, educate, and promote the development and utilization of renewable sources of energy in a country. The board started collection of wind speed data in cooperation with meteorological department. Based on measured meteorological data, the board prepared short-, mid-, and long-term renewable energy deployment goals.

\section{Literature review}

Mostafaeipour et al. [5] conducted feasibility study of wind energy of Shahrbabak, Kaman province, of Iran. The author used two-parameter Weibull distribution function for wind analysis and wind power density for energy generation and concluded that the site is suitable for the installation of small wind energy farm. Mostafaeipour [6] in another work conducted the feasibility study of wind potential of Yazd province of Iran. In this work, the author analyzed the 13-year wind data and used the measured data at the height of $10 \mathrm{~m}$. The study suggested that the site is suitable for wind farm development.

Keyhani et al. [7] investigated the wind climate for the energy production at Tehran, the capital of Iran. In this work, the author used the two-parameter Weibull distribution function for seasonal wind analysis using measured data at the height of $10 \mathrm{~m}$. Kwon [8] investigated the wind uncertainty of a Kwangyang Bay of Chonnam Peninsula of the southern coast of Korea and found 11\% wind uncertainty. The author used probability models for wind variability including air density, surface roughness factor, wind speed, Weibull parameters, and error estimation of long-term wind speed based upon the Measure-Correlate-Predict method for uncertainty analysis.

Mohammadi and Mostafaeipour [9] estimated wind power potential of Zarinah and used the standard deviation and wind power density method to find accurate wind power density at the site. Mostafaeipour et al. [10] investigated the wind power potential of Binalood of Iran and concluded that the site has potential for the wind energy generation. Mirhosseini et al. [11] conducted feasibility 


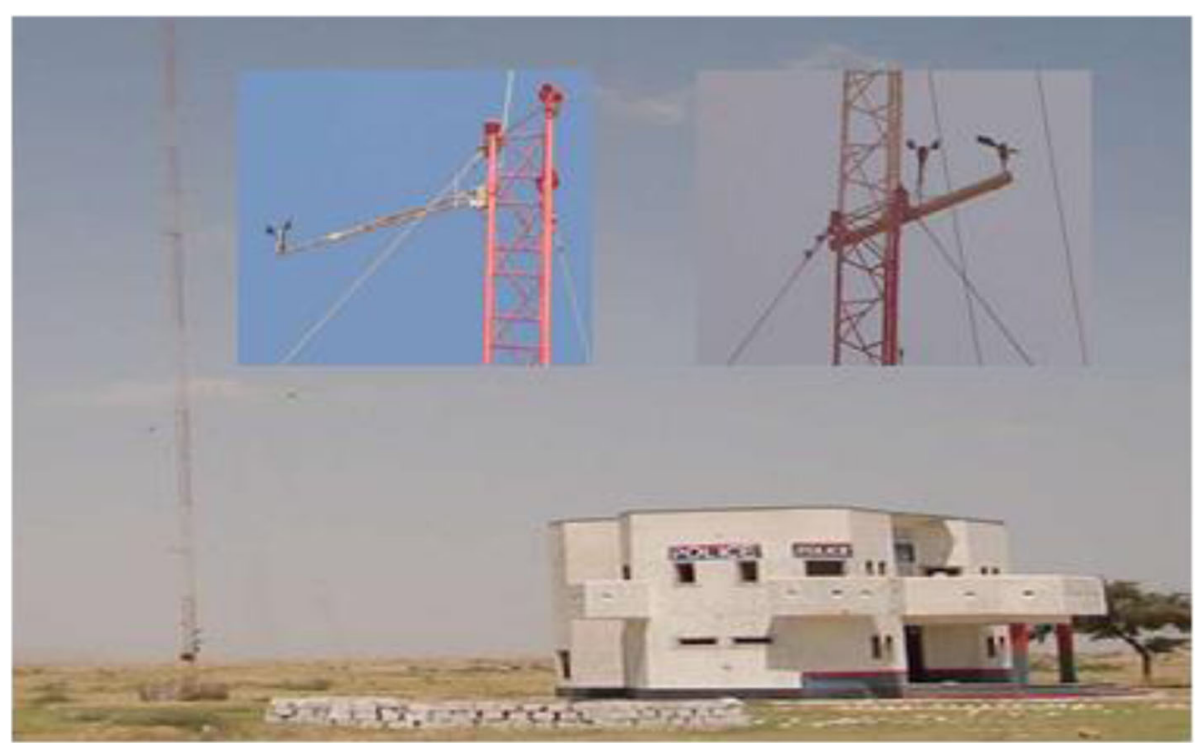

Fig. 4 Nooriabad Met Mast at Super Highway (mounted wind vane)

study of five towns of Saman province of Iran. The study used the wind speed data collected at the heights of 10, 30, and $40 \mathrm{~m}$ respectively. Baseer et al. [12] analyzed the wind resources of seven locations of Jubail, Saudi Arabia. The author used maximum likelihood, least square regression method, and WAsP algorithm.

Dahmouni et al. [13] assessed the wind power potential of Borj Cedria in Tunisia using measured wind speeds at 10-, 20-, and 30-m heights above the ground level. The author used the seven 1.5 MW rated capacity wind turbines for the wind power potential of site. $\mathrm{Li}$ and $\mathrm{Li}$ [14] conducted wind potential of Waterloo, Canada. The authors carried out the annual, monthly, seasonal analysis of wind speed data for realistic wind energy assessment. Lashin and Shata [15] analyzed wind speed data on seasonal, yearly, and monthly basis for energy generation at Port Said in Egypt. The wind energy flux method was used to calculate annual and monthly mean wind speed. Himri et al. [16] investigated 8 years wind speed data of Tindouf, Algeria, for wind resource assessment. The authors used RET screen software and compared the energy production in terms of avoidance of oil results for clean energy. Đurišić and Mikulović [17] studied wind power potential of South Banat region, Serbia. The author developed mathematical model to estimate the vertical wind speed based upon the least square method and concluded that the site is suitable for wind farm.

Ouarda et al. [18] evaluated the wind speed with reference to probability density function and concluded the selection of appropriate pdf to minimize the wind power estimation error. The author used two-parameter Weibull distribution function, parametric models, mixture models, and one nonparametric method using kernel

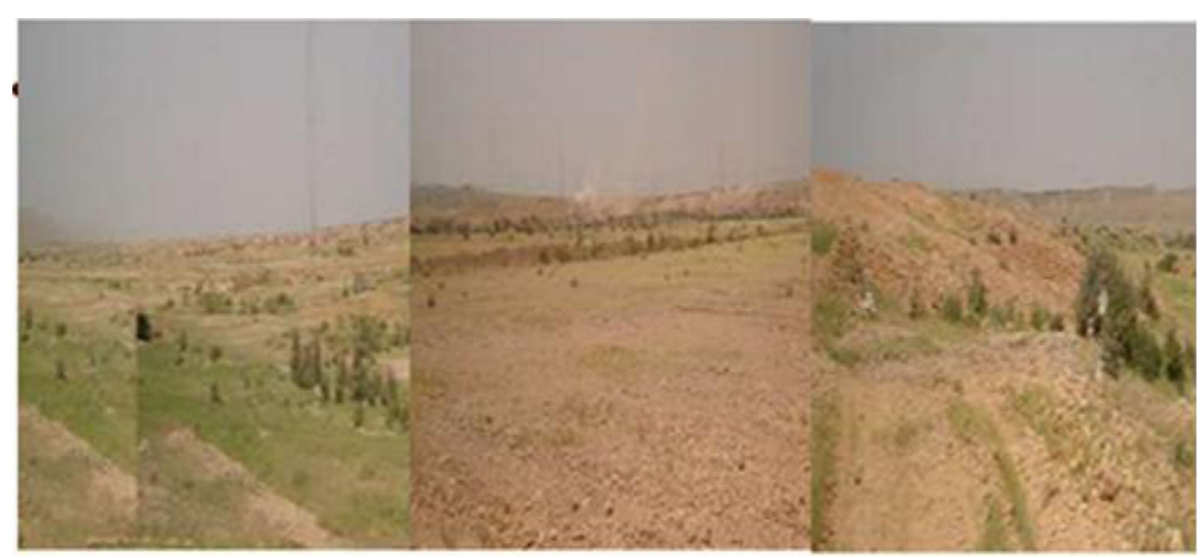

Fig. 5 Panoramic view of Nooriabad 
density method. Rehman and Al-Abbadi $[19,20]$ investigated wind shear and its effects on energy production and concluded the significant influence by the seasonal and diurnal changes. Firtin et al. [21] suggested that accurate determination of wind shear is critical to design and optimization of wind power investment. Wind turbines are constantly subjected to asymmetrical loads like wind shear which will lead to unsteady loading upon the blade and affect its performance [22].

Al-Abbadi [23] investigated wind potential of Yanbu, Saudi Arabia. The wind data analyzed for annual, seasonal, and diurnal and suggested that the site has potential for small wind turbines. Rehman et al. [24] studied wind power potential of seven sites of Saudi Arabia and used Weibull function to study wind characteristics at three different heights. Bassyouni et al. [25] analyzed the wind speed characteristics including daily, monthly, and annual wind speed, and wind probability density distribution, shape and scale parameters at 10-m height, based on 11 years wind data record of Jeddah city of Saudi Arabia.

This paper is focused on detailed analysis of wind speeds measured at 30 and $50 \mathrm{~m}$ above the ground level for a period of 1 year, i.e., 2009 to assess the wind power potential using two-parameter Weibull distribution function. The wind power density, annual wind energy, and capacity factor are calculated at data measurement heights. The Weibull shape and scale parameters are calculated using different methods like empirical, maximum likelihood, modified maximum likelihood, graphical, and energy pattern. The results are evaluated in terms of root mean square error (RMSE) and coefficient of determination $R^{2}$ values. The economic assessment is also carried out to estimate the cost of energy in order to select the best wind turbine.

\section{Wind data measurement site description}

Nooriabad is located on Karachi-Hyderabad super highway. It is an industrial zone of Pakistan. The wind speed measurements were carried out using a wind mast located along with the super highway in Nooriabad as shown in Fig. 4. The geographical location of Nooriabad site is $25^{\circ} 10.906^{\prime} \mathrm{N}$ and $67^{\circ} 48.719 \mathrm{E}$. The site is 3 to $8 \mathrm{~m}$ above the sea level. The terrain is simple and has no major obstacles as shown in Fig. 5. Also, similar terrain is found in west, north, and south, but east has some agricultural land. The site roughness is generally low. Two digital wind speed sensors (model@ 40c NRG) and a temperature sensor (model@110 NRG) are installed at 30- and 50-m heights. The technical specifications of the meteorological sensors are summarized in Table 1. The data was scanned every $0.5 \mathrm{~s}$, and 1-min averaged values along with standard deviations were recorded in the data logger.

\section{Methods}

\section{Wind data analysis}

Wind is the random variable and highly fluctuating meteorological parameter and changes with time of the day, day of the year, and year to year. Probability density function can be used to calculate the wind speed variation over a period of time. Wind data is essential for the investigation of wind potential of specific site, and energy generation can be estimated.

\section{Wind shear}

The wind shear is calculated by the following equation [26]:

$$
\alpha=\frac{\ln \left(V_{2}\right)-\ln \left(V_{1}\right)}{\ln \left(Z_{2}\right)-\ln \left(Z_{1}\right)}
$$

where $V_{1}$ is the wind speed at the height $Z_{1}, V_{2}$ is the wind speed at the height $Z_{2}$, and $\alpha$ is the wind shear coefficient. The wind shear exponent of the site is also calculated using the following empirical equation [27]:

$$
\alpha=\frac{0.37-0.088 \ln (h)}{1-0.088 \times \ln \left(\frac{2}{10}\right)}
$$

\section{Air density}

The air density is expressed as under [20]:

\begin{tabular}{|c|c|c|}
\hline & Wind speed sensor (model \#40) & Temperature sensor (model \#110) \\
\hline Type & 3-cup anemometer & ICT with 6-plate radiation shield \\
\hline Maximum operating range & $1-96 \mathrm{~m} / \mathrm{s}$ (2.2 to $214 \mathrm{mph})$ & $-40-52.5^{\circ} \mathrm{C}\left(-40-126.5^{\circ} \mathrm{F}\right)$ \\
\hline Accuracy & $\pm 0.8 \%$ & $\pm 1.1^{\circ} \mathrm{C}\left(2^{\circ} \mathrm{F}\right)$ \\
\hline Temperature range & $-55-60{ }^{\circ} \mathrm{C}$ & $-40-52.5^{\circ} \mathrm{C}\left(-40-126.5^{\circ} \mathrm{F}\right)$ \\
\hline Distance constant & $3.0 \mathrm{~m}(10 \mathrm{ft})$ & - \\
\hline Output signal range & $0-125 \mathrm{~Hz}$ & $0-2.5 \vee D C$ \\
\hline Weight & 0.14 kg (0.3 lb) & $0.47 \mathrm{~kg}(1.04 \mathrm{lb})$ \\
\hline
\end{tabular}

Table 1 Specification of the wind speed and temperature sensors 
Table 2 Monthly mean wind shear coefficient at a measurement site

\begin{tabular}{|c|c|c|c|c|c|c|c|c|c|c|c|c|}
\hline Jan & Feb & Mar & Apr & May & Jun & Jul & Aug & Sep & Oct & Nov & Dec & Mean \\
\hline 0.269 & 0.265 & 0.26 & 0.23 & 0.208 & 0.195 & 0.2 & 0.205 & 0.233 & 0.275 & 0.289 & 0.272 & 0.24 \\
\hline
\end{tabular}

$$
\rho=\frac{P}{R \times T}\left(\mathrm{~kg} / \mathrm{m}^{3}\right)
$$

where $p$ refers to the air pressure $\left(\mathrm{Pa}\right.$ or $\left.\mathrm{N} / \mathrm{m}^{2}\right), R$ refers to the specific gas constant for air $(287 \mathrm{~J} / \mathrm{kg})$, and $T$ refers to the air temperature in Kelvin $\left(c+273^{\circ}\right)$.

\section{Weibull probability distribution function}

The wind speed can be represented with Weibull distribution function. The two-parameter Weibull distribution function is used to determine the effectiveness of wind potential. The Weibull function is given by the probability density function $f(v)$ as follows [28, 29]:

$$
f(v)=\left(\frac{k}{C}\right)\left(\frac{V}{C}\right)^{k-1} \exp \left[\left(-\frac{V}{C}\right)^{k}\right]
$$

Here, $V$ refers to the wind speed, $k$ refers to the shape parameter, and $c$ refers to the scale parameter. The cumulative distribution function $F(v)$ is given as follows:

$$
f(v)=1-\exp \left[\left(-\frac{V}{C}\right)^{k}\right]
$$

Rayleigh distribution is a special form of Weibull distribution function. In this case, the value of parameter $k$ is fixed as 2 . The probability and cumulative distribution

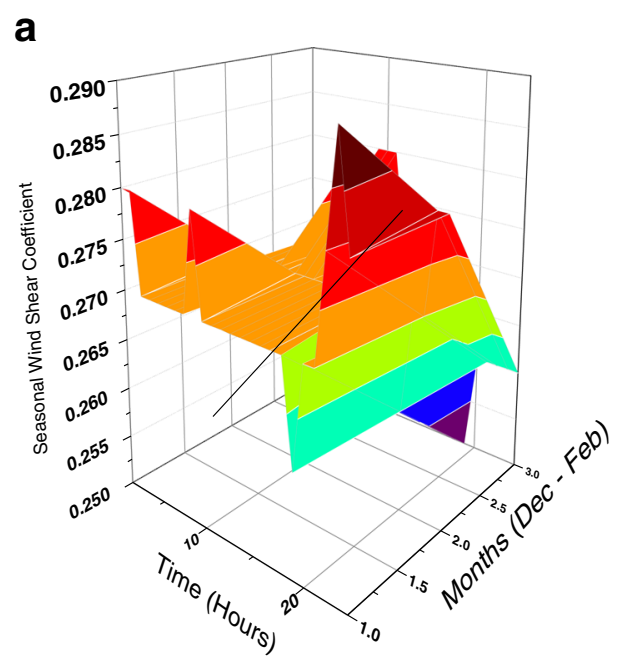

b

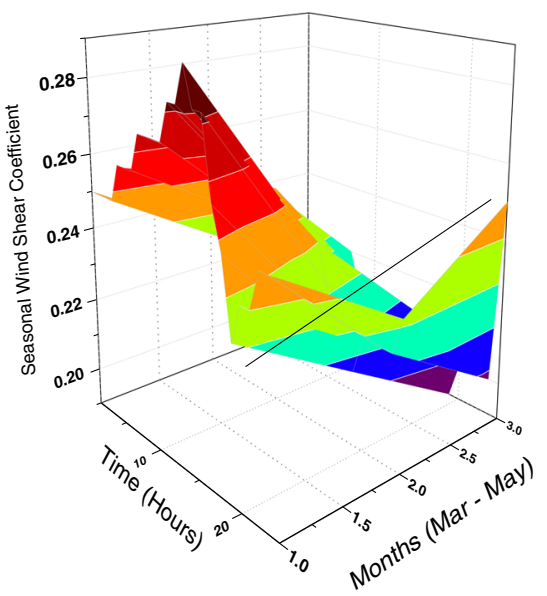

C

d
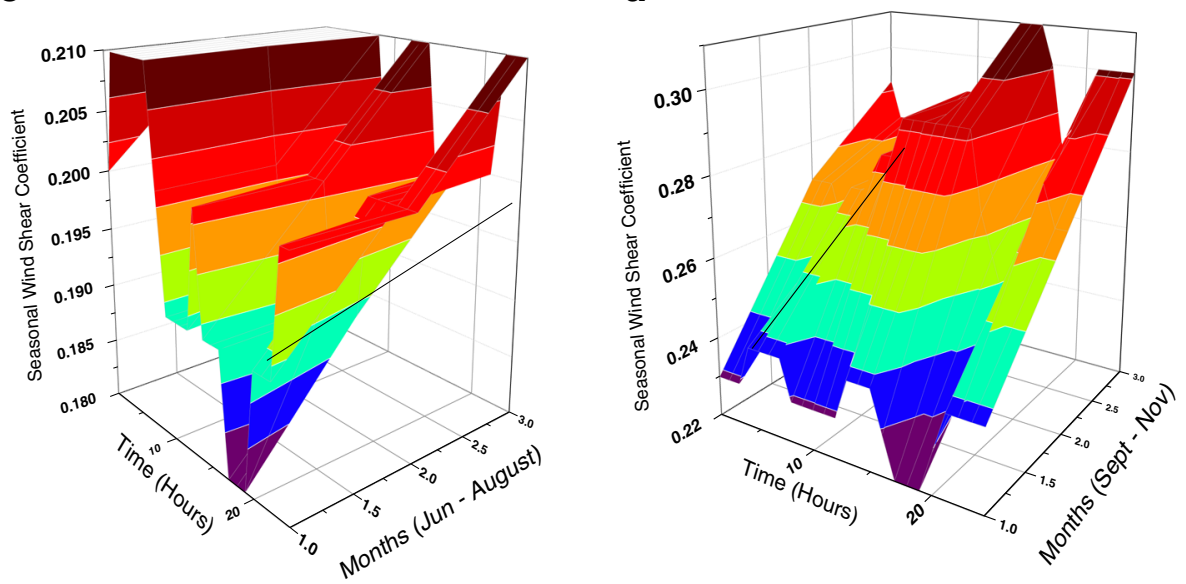

Fig. 6 Mean seasonal wind shear coefficient. a Winter (December-February). b Spring (March-May). c Summer (June-August). d Autumn season (September-November) 
Table 3 Monthly mean diurnal variation of wind speed

\begin{tabular}{|c|c|c|c|c|c|c|c|c|c|c|c|c|}
\hline Jan & Feb & Mar & Apr & May & Jun & Jul & Aug & Sep & Oct & Nov & Dec & Mean \\
\hline 4.26 & 4.45 & 4.62 & 6.05 & 7.92 & 9.50 & 8.22 & 8.30 & 6.08 & 4.01 & 3.55 & 4.11 & 5.92 \\
\hline
\end{tabular}

function can be represented following [30, 31] which is given as follows:

$$
\begin{aligned}
& f(V)=\frac{\pi}{2}\left(\frac{V}{V_{\text {mean }}^{2}}\right) \exp \left[-\left(\frac{\pi}{4}\right)\left(\frac{V}{V_{\text {mean }}^{2}}\right)^{2}\right] \\
& F(V)=1-\exp \left[-\left(\frac{\pi}{4}\right)\left(\frac{V}{V_{\text {mean }}^{2}}\right)^{2}\right]
\end{aligned}
$$

Mean wind speed is used to measure potential of wind energy production and can be termed as $V_{\text {mean }}$ potential. It can be calculated as given in [28] and the wind speed variance $\sigma^{2}$ can be expressed as follows:

$$
V_{\text {mean }}=\frac{1}{N} \sum_{i=1}^{N} V_{i}
$$

$$
\sigma^{2}=\frac{1}{N-1} \sum_{i=1}^{N}\left(V_{i}-V_{\text {avg }}\right)^{2}
$$

The standard deviation can be expressed as follows:

$$
\sigma=\sqrt{\frac{1}{N-1} \sum_{i=1}^{N}\left(V_{i}-V_{\mathrm{avg}}\right)^{2}}
$$

The mean and variance of wind speed can be calculated, using Weibull parameters, as follows [7]:

$$
\begin{aligned}
& V_{\mathrm{avg}}=c \Gamma\left(1+\frac{1}{K}\right) \\
& \sigma^{2}=C^{2}\left[\Gamma\left(1+\frac{2}{K}\right)-\Gamma^{2}\left(1+\frac{2}{K}\right)\right]
\end{aligned}
$$
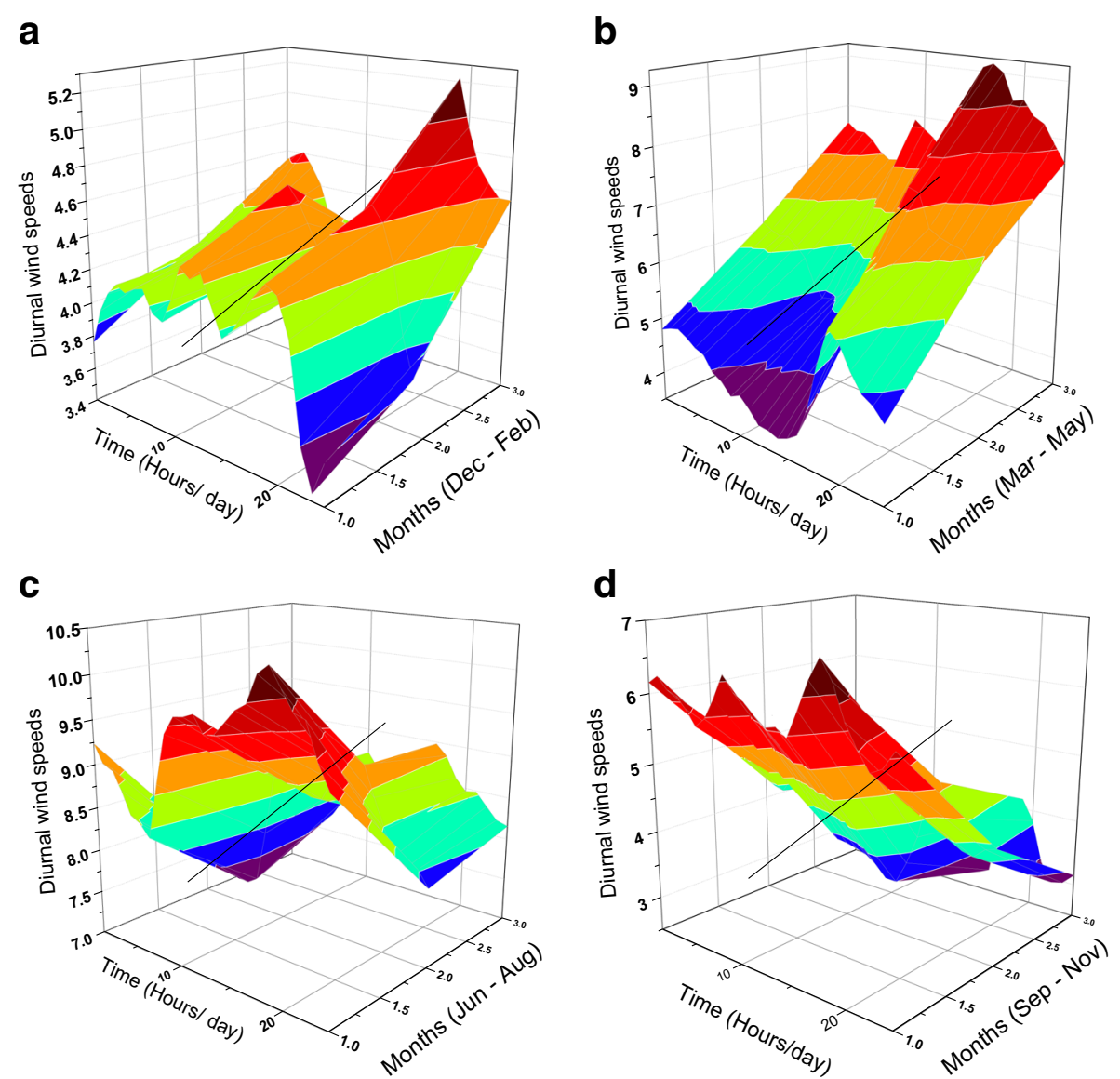

Fig. 7 Mean seasonal and diurnal wind speed. a Winter (December-February). b Spring (March-May). c Summer (June-August). d Autumn season (September-November) 
Here, $\Gamma$ is the gamma function and can be solved by following equation:

$$
\Gamma_{(x)}=\int_{0}^{\infty} e^{-\mu} u^{x-1} d u
$$

\section{Wind power density}

The wind power can be calculated by using the following equation [32]:

$$
P_{W}=\frac{1}{2} \rho A_{T} V^{3}
$$

where $P_{W}$ is the wind power, $V$ is the wind speed, $p$ is the air density, and $A_{T}$ is the swept area of the wind turbine blade. Betz theorem states that less than 59\% $(16 / 27)$ of the kinetic energy can be converted to mechanical energy using wind turbines. The Betz coefficient is denoted by $C_{p}$ and is expressed as follows:

$$
P=\frac{1}{2} \rho C_{p} A_{T} V^{3}
$$

The wind power expressed in context of area (independent of wind turbine area) is termed as wind power density. This can be obtained from Eq. 15, as expressed below [27]:

$$
\mathrm{WPD}=\frac{P}{A}=\frac{1}{2} \rho C_{p} V^{3}
$$

The wind power density with Weibull probability density function can be calculated as follows [33], and the wind energy obtained from the chosen wind turbine can be calculated using Eq. 18 .

$$
\begin{aligned}
& \text { WPD }=\frac{P}{A_{T}}=\frac{1}{2} \rho C_{p^{3}} \Gamma\left(1+\frac{3}{\mathrm{k}}\right) \\
& E=T \int_{0}^{\infty} P(V) \cdot f(V) d(V)
\end{aligned}
$$

where $E$ refers to the energy obtained, $T$ refers to the time period, and $P(V)$ refers to the power curve of wind turbine. Substituting the values of Eq. 4 in Eq. 18, we can find the following equation:

$$
E=T \int\left(\frac{k}{C}\right)\left(\frac{V}{C}\right)^{k-1} \exp \left(-\frac{V}{C}\right)^{k} \cdot p(V) d(V)
$$

The above equation is the Weibull distribution function for achieving the wind energy.

\section{Capacity factor}

Capacity factor is termed as energy output of wind turbine and expressed as follows:

$$
c f=\frac{\text { Actual power from wind turbine }}{\text { Rated power of wind turbine }}
$$

\section{Weibull parameter assessment methods}

There are different parameter estimation methods to determine the Weibull parameters. The Weibull parameters are essential for analyzing the wind power potential and its characteristics. If Weibull parameter obtained precisely, the Weibull distribution not only provides better fit results but also represents wind power potential accurately. The methods used for the estimation of Weibull parameters are given below.

\section{Empirical method}

Empirical method is derived from the method of moments. It is a collection of data points. Weibull shape and scale parameters, $k$ and $c$, are calculated by using Eqs. 21 and 22.

$$
\begin{aligned}
& k=\left(\frac{\sigma}{V_{\text {avg }}}\right)^{-1.086} \\
& c=\frac{V_{\text {avg }}}{\Gamma\left(1+\frac{1}{k}\right)}
\end{aligned}
$$

\section{Maximum likelihood method}

The maximum likelihood method can be used to determine the Weibull parameters $k$ and $c$. The shape $k$ and scale $c$ parameters are calculated as follows:

$$
\begin{aligned}
& k=\left[\frac{\sum_{i=1}^{N} V_{i}^{K} \ln \left(V_{i}\right)}{\sum_{i=1}^{N} V_{i}^{K}}-\frac{\sum_{i=1}^{N} \ln \left(V_{i}\right)}{N}\right]^{-1} \\
& c=\left(\frac{1}{N} \sum_{i=1}^{N} V_{i}^{k}\right)^{\frac{1}{K}}
\end{aligned}
$$

where $N$ is number of wind speed data points and $V_{i}$ is a wind speed value for the $i$ th data measurement.

\section{Modified maximum likelihood method}

The following modified equations of $k$ and $c$ are used to determine the values of shape $k$ and scale $c$ parameters as follows:

$$
k=\left[\frac{\sum_{i=1}^{N} V_{i}^{k} \ln \left(V_{i}\right)+\left(V_{i}\right)}{\sum_{i=1}^{N} V_{i}^{k} f\left(V_{i}\right)}-\frac{\sum_{i=1}^{N} \ln \left(V_{i}\right) f\left(V_{i}\right)}{f(V \geq 0)}\right]^{-1}
$$




$$
c=\left(\frac{1}{f(\geq 0} \sum_{i=1}^{n} v_{i}^{k} P\left(v_{i}\right)\right) \frac{1}{k}
$$

\section{Energy pattern method}

The energy factor method is related to mean wind speed and can be calculated as [34]:

$$
E_{f m}=\frac{\left(V^{3}\right)_{\mathrm{avg}}}{\left(V_{\mathrm{avg}}\right)^{3}}
$$

Shape and scale parameters are calculated using the energy pattern method is follows:

$$
\begin{aligned}
& k=1+\frac{3.69}{\left(E_{f m}\right)^{2}} \\
& c=\frac{V_{\mathrm{avg}}}{\Gamma\left(1+\frac{1}{k}\right)}
\end{aligned}
$$

\section{Graphical method}

Graphical method is implemented by using least square to fit the straight line to wind data. This can be expressed as follows [35]:

$$
\ln [-\ln (1-F(V))]=k \ln V-k \ln c
$$

The linear equation is expressed as follows:

$$
\begin{aligned}
& y=\ln [-\ln (1-F(V))] \\
& x=\ln V, a=k, \text { and } b=-k \ln c
\end{aligned}
$$

where $a$ refers to slope and $b$ is the intercept line and can be obtained by least square regression method. The values of the shape and scale, $k$ and $c$, can be calculated by [36]:

$$
k=a, C=e^{-\frac{b}{k}}
$$

\section{Statistical error analysis and goodness for fit}

The statistical error analysis method is used to examine the accuracy and viability of used methods. To test the results of the above methods, the following tests are used [36]:

$$
R^{2}=\frac{\sum_{i=1}^{N}\left(Y_{i}-z\right)^{2}-\sum_{I=1}^{N}\left(x_{i}-z\right)^{2}}{\sum_{i=1}^{N}\left(Y_{i}-z\right)^{2}}
$$

Root mean square error is expressed as follows:

$$
\text { RMSE }=\left[\frac{1}{n} \sum_{i=1}^{N}\left(y_{i}-x_{i}\right)^{2}\right]^{1 / 2}
$$

\section{Economic analysis of wind turbine}

Let $I$ be the initial investment, $C_{o m}$ the operation and maintenance cost which is $n \%$ of initial investment, and $T$ the life time of the wind turbine. The discounted costs of operation and maintenance for life time $T$ of wind turbine for an initial year, net present worth (NPW), and the total cost (Tc) of the energy can be calculated by [5]:

$$
\begin{aligned}
& P C_{o m_{1-t}}=I\left[\left[\frac{\left(1+i_{r}\right)^{t}-1}{i_{r}\left(1+i_{r}\right)}\right]\right] \\
& P W_{1-t}=I\left[I+n\left\{\frac{\left(1-i_{r}\right)^{t}-1}{i_{r}\left(1+i_{r}\right)^{t}}\right\}\right] \\
& \mathrm{NPW}=\frac{P W_{1-t}}{t}=\frac{1}{t}\left[I+n\left\{\frac{\left(1-i_{r}\right)^{t}-1}{i_{r}\left(1+i_{r}\right)^{t}}\right\}\right]
\end{aligned}
$$

The total cost of wind energy can be calculated from the following equation:

$$
T_{c}=\frac{P W}{E}
$$

In Eq. 39, $E$ is the energy generated by wind turbines annually and is obtained using the Eq. 40 [5]:

$$
\begin{aligned}
& E=T_{a h} \times R_{p} \times C_{f} \\
& E=\frac{1}{T_{a h}}\left(\frac{1}{R_{p} C_{f}}\right)\left[\left[I+n\left\{\frac{\left(1-i_{r}\right)^{t}-1}{i_{r}\left(1+i_{r}\right)^{t}}\right\}\right]\right]
\end{aligned}
$$

\section{Results and discussion}

In this paper, the site-specific technical and economic assessment of the wind power potential has been carried out for an industrial city Nooriabad in Pakistan. The measured wind data is considered for a period of 1 year from January 2009 to December 2009 at 30- and 50-m heights. The results of study are discussed below.

\section{Site-specific wind shear}

Wind shear is a rate of change of speed and direction of wind. The wind shear exponent is highly site dependent and also changes with time of the year. It is very useful in providing the wind speed at higher heights using the measured values of the previous height. The performance of wind turbine is affected by wind shear. Rehman and Al-Abbadi [19] analyzed the effects wind shear on energy production. Firtin et al. [21] described the importance of accurate determination of wind shear and stated that is critical for near reality assessment of wind energy yield. The mean wind shear coefficient for Nooriabad is 0.24 as given in Table 2 . The monthly average wind shear varies between a minimum of 0.195 in June and a maximum of 0.289 in November. Furthermore, the seasonal values of wind shear exponent varied with 


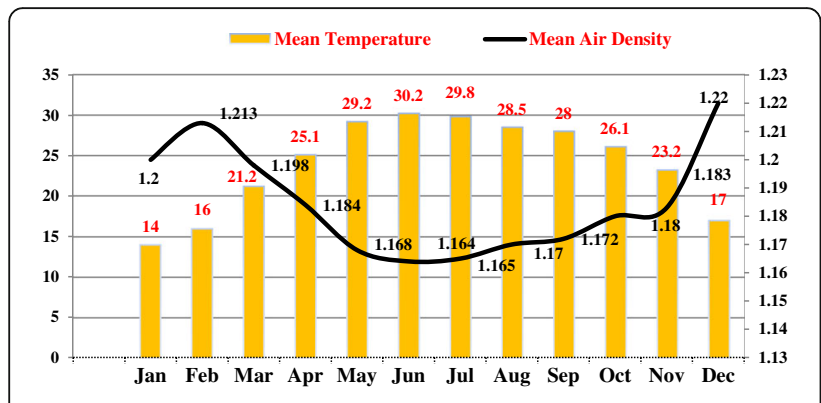

Fig. 8 Monthly mean temperature $\left({ }^{\circ} \mathrm{C}\right)$ and air density $\left(\mathrm{kg} / \mathrm{m}^{3}\right)$

the time of the day, as shown in Fig. 6. In winter season (December-February), the wind shear exponent values were found between 0.265 and 0.285 during early hours of the day while around 0.25 at 10:00 h, as can be seen from Fig. 6a. This diurnal change in wind shear exponent is seen to be different from season to season of the year. The seasonal wind shear values were found to be $0.268,0.232,0.200$, and 0.265 for winter (DecemberFebruary), spring (March-May), summer (June-August), and autumn (September-November), respectively. The wind shear coefficient found maximum during winter season and minimum in summer season.

\section{Seasonal and diurnal variation of wind speed}

The hourly mean values of the recorded data were used to obtain the diurnal and the monthly variations. The mean wind speed was found to be $5.92 \mathrm{~m} / \mathrm{s}$ for a period of 1 year 2009 which is given in Table 3. The average seasonal diurnal wind speeds were found to be $4.27,6.19,8.67$, and $4.55 \mathrm{~m} / \mathrm{s}$ for winter, spring, summer, and autumn seasons, respectively. The highest monthly mean wind speeds were found to be $9.5 \mathrm{~m} / \mathrm{s}$ in June and the lowest of $3.55 \mathrm{~m} / \mathrm{s}$ in November. During summer season, the temperature of region, during the day time, is high $35^{\circ}$. However, from

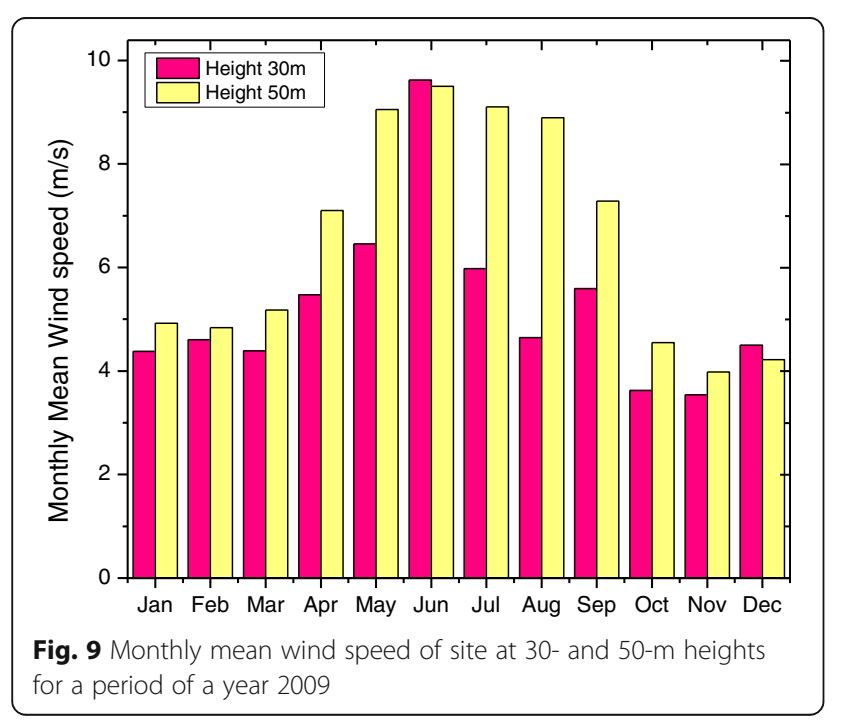

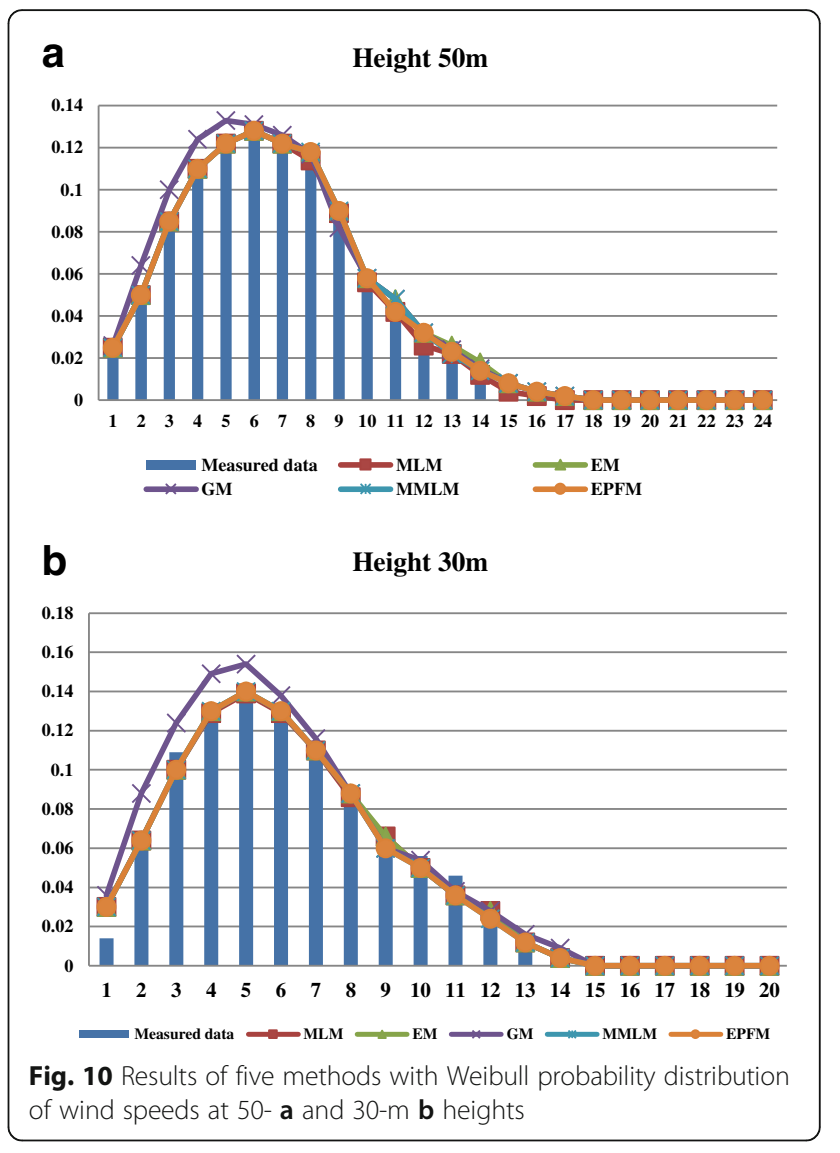

October to December, the temperature again comes down and affects the diurnal wind speed. The observed diurnal wind speed data of Nooriabad site for a year is given in Fig. 7.

\section{Monthly mean temperature and air density variations}

Wind power density is directly related to air density, and hence, higher air density means more wind power density. Accordingly, the air density is higher in winter months and lowers in summer time. The mean values of ambient temperature and the air density are shown in Fig. 8. It is evident from Fig. 8 that the air density decreases with temperature. The monthly mean temperature value were observed to be highest and lowers in the months of June and January while the air density was highest in December and lowest in June, as can be seen from Fig. 8 . The overall mean values of air density found to be $1.189 \mathrm{~kg} / \mathrm{m}^{3}$ over the data collection period. The seasonal values of air density were found to be $1.211,1.183,1.166$, and $1.178 \mathrm{~kg} / \mathrm{m}^{3}$ during winter, spring, summer, and autumn, respectively.

\section{Wind speed variation at different heights}

The wind measurements were made at 30 and $50 \mathrm{~m}$ above the ground level for a period of 1 year in 2009 . 


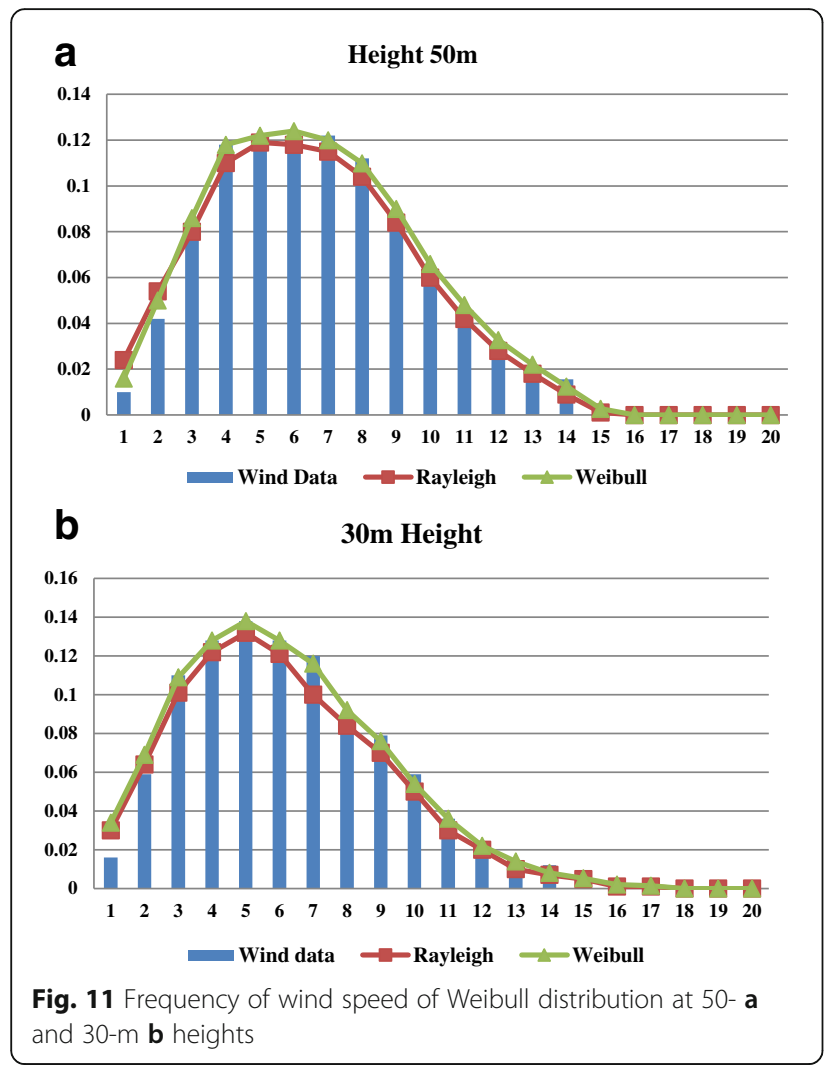

The monthly mean values of the wind speed are shown in Fig. 9 at both the measurement heights. The overall mean wind speeds were found to be 5.23 and $6.55 \mathrm{~m} / \mathrm{s}$ over entire period of data measurements at $30-$ and $50-\mathrm{m}$ heights, respectively. The maximum wind speed of $9.62 \mathrm{~m} / \mathrm{s}$ was observed in June while a minimum of $3.54 \mathrm{~m} / \mathrm{s}$ in November at $30 \mathrm{~m}$. On the other hand, at $50-\mathrm{m}$ height, the minimum and maximum wind speeds of 3.98 and $9.50 \mathrm{~m} /$ $\mathrm{s}$ were found in November and June.
The seasonal average wind speed were found to be $4.495,5.439,6.748$, and $4.251 \mathrm{~m} / \mathrm{s}$ during winter, spring, summer, and autumn seasons at a height of $30 \mathrm{~m}$, respectively. The average seasonal wind speeds at $50-\mathrm{m}$ height were found to be 4.66, 7.11, 9.16, and $5.27 \mathrm{~m} / \mathrm{s}$ in winter, spring, summer, and autumn, respectively. Higher wind speeds were noticed during summer season at both the heights. The wind speed was also analyzed using the concept of most probable wind speed. Accordingly, the highest values of 9.62 and $9.5 \mathrm{~m} / \mathrm{s}$ of most probable winds were found in June at 30 and $50 \mathrm{~m}$, respectively.

In this paper, two-parameter Weibull distribution function is used to assess the wind power potential at the measurement site and determine the effectiveness of different methods used for the estimation of shape and scale parameters. Weibull distribution function provides the better fit to measured wind speed data and effective in analyzing the wind potential for energy production. The value of scale parameter $c$ also changes with time and location like the wind speed. The shape parameter is dimensionless parameter. A value of $k$ between 1 and 2 is an indicative of low wind. If the value of $k$ factor showing increasing tendency, the distribution can be considered as skewed to high level of winds. In simple words, both parameters have to be considered for getting the near accurate results.

The Weibull $k$ and $c$ parameters are estimated using five methods including empirical, maximum likelihood, graphical, modified maximum likelihood, and energy pattern for wind speed data measured at two heights 30 and $50 \mathrm{~m}$. The values of shape and scale parameters obtained using five methods were used to fit the measured wind speed data in different wind speed bins, as shown in Fig. 10. It is evident from Fig. 10 that all the models fitted very well with the measured wind speed data except GM model. Figure 11 shows the comparison between Weibull and Rayleigh distribution of wind speeds

Table 4 Site-specific wind speed, standard deviation, and Weibull $k$ and c parameters for a period of a year from January-December 2009

\begin{tabular}{|c|c|c|c|c|c|c|c|c|c|c|c|c|c|}
\hline PM & Jan & Feb & Mar & Apr & May & Jun & Jul & Aug & Sep & Oct & Nov & Dec & Mean \\
\hline \multicolumn{14}{|c|}{ Height $30 \mathrm{~m}$} \\
\hline$W_{S}$ & 4.38 & 4.607 & 4.392 & 5.47 & 6.455 & 9.62 & 5.98 & 4.644 & 5.589 & 3.626 & 3.54 & 4.498 & 5.233 \\
\hline$\sigma$ & 2.246 & 2.241 & 1.789 & 2.406 & 2.729 & 3.038 & 2.646 & 2.37 & 2.438 & 1.506 & 2.032 & 2.11 & 2.295 \\
\hline k & 2.057 & 2.71 & 2.66 & 2.432 & 2.537 & 2.92 & 2.394 & 2.055 & 2.497 & 2.588 & 1.757 & 2.246 & 2.4 \\
\hline c & 4.942 & 5.198 & 4.955 & 6.172 & 7.283 & 10.85 & 6.747 & 5.24 & 6.307 & 4.0916 & 3.994 & 5.076 & 5.9 \\
\hline \multicolumn{14}{|c|}{ Height 50 m } \\
\hline$W_{S}$ & 4.92 & 4.84 & 5.18 & 7.1 & 9.05 & 9.5 & 9.1 & 8.89 & 7.28 & 4.55 & 3.98 & 4.22 & 6.55 \\
\hline$\sigma$ & 2.349 & 2.67 & 2.369 & 2.145 & 2.255 & 2.282 & 2.256 & 2.051 & 2.157 & 1.965 & 1.57 & 2.049 & 2.176 \\
\hline k & 2.217 & 1.926 & 2.254 & 3.884 & 4.299 & 4.32 & 4.296 & 4.56 & 3.957 & 2.461 & 2.643 & 2.177 & 3.25 \\
\hline c & 5.551 & 5.4615 & 5.845 & 8.011 & 10.22 & 10.72 & 10.268 & 10.032 & 8.2148 & 5.134 & 4.491 & 4.761 & 7.392 \\
\hline
\end{tabular}


Table 5 Wind power density $\left(\mathrm{W} / \mathrm{m}^{2}\right)$ and energy density $\left(\mathrm{kWh} / \mathrm{m}^{2}\right)$ at 50 and $30 \mathrm{~m}$ for a period of a year 2009

\begin{tabular}{|c|c|c|c|c|c|c|c|c|c|c|c|c|c|}
\hline PM & Jan & Feb & Mar & Apr & May & Jun & Jul & Aug & Sep & Oct & Nov & Dec & Mean \\
\hline \multicolumn{14}{|l|}{$50 \mathrm{~m}$} \\
\hline $\mathrm{W} / \mathrm{m}^{2}$ & 135 & 129 & 158 & 406 & 842 & 974 & 856 & 798 & 438 & 107 & 72 & 85 & 416.7 \\
\hline $\mathrm{kWh} / \mathrm{m}^{2}$ & 465 & 438 & 535 & 1096 & 1622 & 1648 & 1630 & 1587 & 1148 & 368 & 237 & 289 & 921.9 \\
\hline \multicolumn{14}{|l|}{$30 \mathrm{~m}$} \\
\hline $\mathrm{W} / \mathrm{m}^{2}$ & 76 & 88 & 76 & 147 & 242 & 800 & 192 & 90 & 157 & 43 & 40 & 82 & 169.4 \\
\hline $\mathrm{kWh} / \mathrm{m}^{2}$ & 289 & 333 & 289 & 526 & 763 & 1438 & 649 & 342 & 552 & 167 & 149 & 316 & 484.4 \\
\hline
\end{tabular}

over frequency distribution at 30 - and 50-m heights. However, it is observed from Fig. 11 that Weibull distribution gave better fitting results than Rayleigh distribution for wind data gathered at the Nooriabad site.

The Weibull distribution parameters $k$ and $c$ and standard deviation at the two heights are summarized in Table 4 . The average values of $k$ and $c$ parameters, obtained using entire data set, were found to be 2.4 and $5.90 \mathrm{~m} / \mathrm{s}$ at $30 \mathrm{~m}$ and 3.25 and $7.39 \mathrm{~m} / \mathrm{s}$ at $50 \mathrm{~m}$, as given in Table 4 . The monthly mean values of $k$ varied between a minimum of 1.757 and a maximum of 2.92 corresponding to November and June, respectively. The seasonal values of shape parameter were 2.337, 2.543, 2.456 , and 2.280 in winter, spring, summer and autumn at $30 \mathrm{~m}$, respectively. The maximum value of shape parameter $k$ was found to be 2.543 during the spring and the lowest 2.28 in autumn. Similarly, the monthly and seasonal mean values of shape parameter $k$ at $50-\mathrm{m}$ height are also included in Table 4.

The scale parameter values for each month over an entire data collection period and at both measurement heights are provided in Table 4 . In general, higher values of $c$ were observed in summer months and lower during winter time. Accordingly at $30 \mathrm{~m}$, a minimum value of $3.99 \mathrm{~m} / \mathrm{s}$ was observed in November while a maximum of $10.850 \mathrm{~m} / \mathrm{s}$ in June. Similarly at 50-m height, the scale parameter values varied between a minimum of $4.491 \mathrm{~m} / \mathrm{s}$ and maximum of $10.72 \mathrm{~m} / \mathrm{s}$ corresponding to

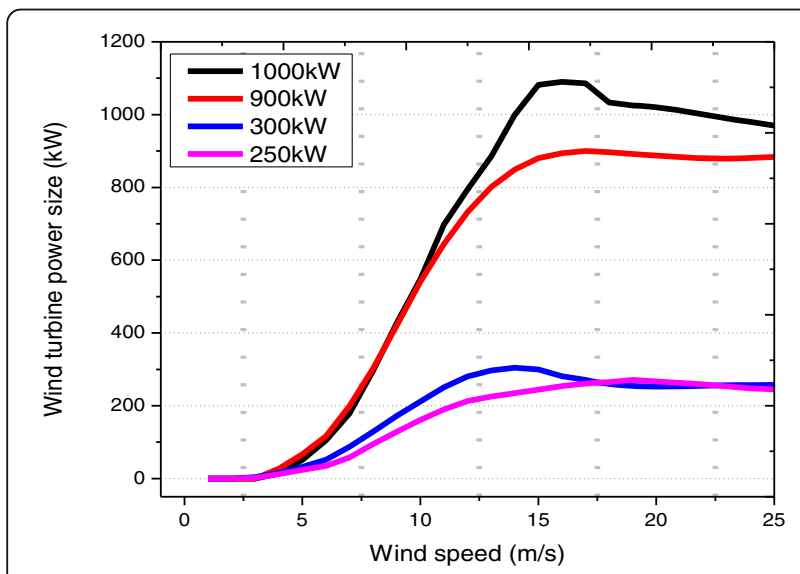

Fig. 12 Manufacturer stated power curve of wind turbines
November and June months of the year. The average seasonal values of $c$ parameter were found to be 5.072, 6.137, 7.612, and $4.797 \mathrm{~m} / \mathrm{s}$ for winter, spring, summer, and autumn, respectively, at $30 \mathrm{~m}$ while 5.25, 8.025, 10.34 , and $5.94 \mathrm{~m} / \mathrm{s}$ at $50 \mathrm{~m}$.

The standard deviation values over an entire data collection period are given in Table 4. The average standard deviation was found to be 2.295 and 2.176 for 1 year at 30 and $50 \mathrm{~m}$. The seasonal calculation showed variation over a period of time. The standard deviation was found to be $2.199,2.308,2.684$, and 1.992 in winter, spring, summer, and autumn at $30 \mathrm{~m}$, respectively. Similarly, the standard deviation was found to be 2.356, 2.256, 2.196, and 1.897 in winter, spring, summer, and autumn at $50 \mathrm{~m}$, respectively.

\section{Calculation of wind power density and energy}

The wind power density was calculated for a period of 1 year at 30 and $50 \mathrm{~m}$ given in Table 5 . The average wind power density was found to be $169.4 \mathrm{~W} / \mathrm{m}^{2}$ at $30-\mathrm{m}$ height. The highest wind power density value was found to be $800 \mathrm{~W} / \mathrm{m}^{2}$ in June and lowest of $40 \mathrm{~W} / \mathrm{m}^{2}$ in November at $30 \mathrm{~m}$. Similarly, the seasonal wind power density was found to be $82,155,360.6$, and $80 \mathrm{~W} / \mathrm{m}^{2}$ in winter, spring, summer, and autumn at $30 \mathrm{~m}$. The highest wind power density found in summer and lowest in autumn at $30 \mathrm{~m}$. The average wind power density was found to be $416.7 \mathrm{~W} / \mathrm{m}^{2}$ at $50 \mathrm{~m}$. The wind power density increased by $40.65 \%$ at $50 \mathrm{~m}$ compared to that of $30 \mathrm{~m}$. The highest wind power density was found to be $974 \mathrm{~W} / \mathrm{m}^{2}$ while lowest $72 \mathrm{~W} / \mathrm{m}^{2}$ in June and November at $50 \mathrm{~m}$. The seasonal wind power densities were found to be $116.4,468.7,876$, and $205.7 \mathrm{~W} / \mathrm{m}^{2}$ in winter, spring, summer, and autumn at $50 \mathrm{~m}$.

The average wind energy density was found to be $484.4 \mathrm{kWh} / \mathrm{m}^{2}$ at $30 \mathrm{~m}$ as given in Table 5 . The highest wind energy density was found to be $1438 \mathrm{kWh} / \mathrm{m}^{2}$ in June and the lowest of $149 \mathrm{kWh} / \mathrm{m}^{2}$ in November at $30 \mathrm{~m}$. The average seasonal wind energy density was found to be $312.7,526,809.7$, and $289.4 \mathrm{kWh} / \mathrm{m}^{2}$ during winter, spring, summer, and autumn at $30 \mathrm{~m}$. The average wind energy density was found to be $921.9 \mathrm{kWh} / \mathrm{m}^{2}$ at $50 \mathrm{~m}$. The wind energy density increased by $52.54 \%$ at $50 \mathrm{~m}$ compared to that of $30 \mathrm{~m}$. The highest wind 
Table 6 Wind turbines energy yield and capacity factor for a period of a year 2009

\begin{tabular}{|c|c|c|c|c|c|c|c|c|c|c|c|c|c|}
\hline PM & Jan & Feb & Mar & Apr & May & Jun & Jul & Aug & Sep & Oct & Nov & Dec & Mean \\
\hline \multicolumn{14}{|c|}{ Wind turbine $1(1000 \mathrm{~kW})$} \\
\hline GWh & 0.94 & 0.9 & 1.1 & 2.45 & 3.75 & 4.01 & 3.8 & 3.68 & 2.57 & 0.75 & 0.5 & 0.85 & 25.4 \\
\hline CF & 12 & 12 & 14 & 30 & 45 & 46 & 45 & 43 & 32 & 10 & 6 & 9 & 25.33 \\
\hline \multicolumn{14}{|c|}{ Wind turbine 2 (900 kW) } \\
\hline GWh & 0.98 & 0.93 & 1.13 & 2.32 & 3.44 & 3.5 & 3.46 & 3.37 & 2.43 & 0.78 & 0.5 & 0.61 & 23.5 \\
\hline CF & 13 & 12 & 14 & 29 & 44 & 44 & 44 & 43 & 31 & 10 & 6 & 8 & 24.83 \\
\hline \multicolumn{14}{|c|}{ Wind turbine 3 (300 kW) } \\
\hline GWh & 0.253 & 0.291 & 0.253 & 0.46 & 0.67 & 1.26 & 0.57 & 0.3 & 0.48 & 0.14 & 0.13 & 0.27 & 5.09 \\
\hline CF & 10 & 11 & 10 & 18 & 25 & 48 & 22 & 11 & 18 & 6 & 5 & 11 & 16.25 \\
\hline \multicolumn{14}{|c|}{ Wind turbine 4 (250 kW) } \\
\hline GWh & 0.17 & 0.21 & 0.17 & 0.33 & 0.5 & 0.99 & 0.41 & 0.21 & 0.35 & 0.09 & 0.08 & 0.18 & 3.69 \\
\hline CF & 8 & 9 & 8 & 15 & 22 & 45 & 19 & 10 & 16 & 4 & 4 & 8 & 14 \\
\hline
\end{tabular}

energy density was found to be $1648 \mathrm{kWh} / \mathrm{m}^{2}$ in June and the lowest $237 \mathrm{kWh} / \mathrm{m}^{2}$ in November at $50 \mathrm{~m}$. The average seasonal wind energy density was found to be $397.4,1084.4,1621.7$, and $584.4 \mathrm{kWh} / \mathrm{m}^{2}$ during winter, spring, summer, and autumn at $50 \mathrm{~m}$. For $50 \mathrm{~m}$, the highest energy density was found in summer and lowest in winter.

The power curves of the chosen wind turbines are given in Fig. 12. For optimal performance, the design parameters of wind turbine including cut in and cut out speed, hub height, and rated power are chosen according to wind characteristics of candidate site. The performance of wind turbine is based on not only the wind characteristics of site but also distribution of wind speed. In this paper, the performance assessment of four different wind turbines is carried out for the candidate site. The rated powers of these wind turbines ranged from 250 to $1000 \mathrm{~kW}$. The total energy output and capacity factor of wind turbines is given in Table 6 . The average minimum capacity factor was $14 \%$ for wind turbine number 4 while maximum of $25.33 \%$ for wind turbine number 1 . The maximum annual energy of 25.4 GWh was produced by wind turbine 1 while minimum of $3.69 \mathrm{GWh}$ by wind turbine 4 , respectively. The objectives of using wind turbines of different origins are to analyze the wind power potential and also give clear picture in terms of choosing the suitable wind turbine for site.

\section{Economic assessment}

The economic assessment is essential while investing huge amount in installation of utility scale wind turbines for wind power production. At initial, the first sitespecific wind characteristic analysis is carried out and then selection of wind turbines examined while considering mechanical configuration of turbine suited to the site. The economic assessment for a Nooriabad site is given in Table 7. The estimated cost of utility wind turbines, as per rule of thumb $[37,38]$, is US $\$ 1000 / \mathrm{kW}$. The installation cost is taken as a $20 \%$ and operation and the annual maintenance cost as $2 \%$ of the wind turbine cost. The estimated wind turbine life is considered as 20 years and a real interest rate of $5 \%$.

The wind turbines have been selected and analyzed, according to their mechanical configuration. According to the results, the wind turbine 1 is capable of producing wind energy at the lowest value of US $\$ 0.02189 / \mathrm{kWh}$, as given in Table 7.

\section{Conclusions}

In this paper, the wind power potential of Nooriabad is studied by using the wind measurements for a period of 1 year in 2009 at 30- and 50-m heights. The mean wind shear coefficient and air density were found to be 0.24 and $1.189 \mathrm{~kg} / \mathrm{m}^{3}$, respectively. The measured mean wind speed was found to be 5.233 and $6.55 \mathrm{~m} / \mathrm{s}$ at 30 and $50 \mathrm{~m}$, respectively. The Weibull $k$ parameter was found to be 2.4 and 3.24, while $c$ parameter was found to be 5.9 and 7.392 at 30 and $50 \mathrm{~m}$, respectively. The average values of standard deviation were found to be 2.295 and 2.176 at 30 and $50 \mathrm{~m}$. In this paper, two-parameter Weibull distribution function is used to assess the wind power potential at the measurement site and determine the effectiveness of different methods used for the estimation of shape and scale parameters. Weibull distribution function provides the better fit to measured wind speed data and effective in analyzing the wind potential

Table 7 Economic analysis of wind turbines

\begin{tabular}{llll}
\hline & $E_{p}(G W h)$ & CF & Cost/kWh (US\$) \\
\hline WT 1 & 25.4 & 25.3 & 0.02189 \\
WT 2 & 23.5 & 24.83 & 0.0228 \\
WT 3 & 5.09 & 16.25 & 0.0336 \\
WT 4 & 3.69 & 14 & 0.0387 \\
\hline
\end{tabular}


for energy production. The methods used including empirical (EM), maximum likelihood (MLM), modified maximum likelihood (MMLM), and energy pattern (EPEM) were fitted very well except the graphical method (GM). Weibull distribution gave better fitting results than Rayleigh distribution for wind data gathered at the Nooriabad site. The mean wind power density was found to be 169.9 and $416.7 \mathrm{~W} / \mathrm{m}^{2}$ at 30 and $50 \mathrm{~m}$. The annual energy density was found to be 484.4 and $921.94 \mathrm{~kW} / \mathrm{m}^{2}$ at 30 and $50 \mathrm{~m}$. Wind turbine 1 has the highest energy yield of $25.4 \mathrm{GWh}$ and has the lowest cost of energy generation of US $\$ 0.02189 / \mathrm{kWh}$. The assessment of wind potential shows that the site has potential for installation of wind turbines for energy generation.

\section{Authors' contributions}

The main idea of this paper was proposed and written by ZHH and WJ. The paper was thoroughly revised by SR. All authors read and approved the final manuscript.

\section{Competing interests}

The authors declare that they have no competing interests.

\section{Publisher's Note}

Springer Nature remains neutral with regard to jurisdictional claims in published maps and institutional affiliations.

\section{Author details}

${ }^{1}$ School of Mechanical Engineering, Dalian University of Technology, Dalian, Liaoning 116024, China. ${ }^{2}$ Centre for Engineering Research, Research Institute, King Fahd University of Petroleum and Minerals, Dhahran 31261, Saudi Arabia.

Received: 17 May 2017 Accepted: 6 October 2017

Published online: 06 November 2017

\section{References}

1. Global Wind Statistics, GWEC (2016) http://www.gwec.net/wp-content/ uploads/2017/02/1_Global-Installed-Wind-Power-Capacity-MW-\%E2\%80\%93Regional-Distribution.jpg. Accessed on 28 Feb 2017.

2. Sheikh MA (2010) Energy and renewable energy scenario of Pakistan. Renew Sust Energ Rev 14(1):354-363

3. Shaikh F, Ji Q, Fan Y (2015) The diagnosis of an electricity crisis and alternative energy development in Pakistan. Renew Sust Energ Rev 52:1172-1185

4. Shami SH et al (2016) Evaluating wind energy potential in Pakistan's three provinces, with proposal for integration into national power grid. Renew Sust Energ Rev 53:408-421

5. Mostafaeipour A et al (2011) Wind energy feasibility study for city of Shahrbabak in Iran. Renew Sust Energ Rev 15(6):2545-2556

6. Mostafaeipour A (2010) Feasibility study of harnessing wind energy for turbine installation in province of Yazd in Iran. Renew Sust Energ Rev 14(1): 93-111

7. Keyhani A et al (2010) An assessment of wind energy potential as a power generation source in the capital of Iran. Tehran Energy 35(1):188-201

8. Kwon S-D (2010) Uncertainty analysis of wind energy potential assessment. Appl Energy 87(3):856-865

9. Mohammadi K, Mostafaeipour A (2013) Using different methods for comprehensive study of wind turbine utilization in Zarrineh, Iran. Energy Convers Manag 65:463-470

10. Mostafaeipour A et al (2013) Evaluation of wind energy potential as a power generation source for electricity production in Binalood, Iran. Renew Energy 52:222-229

11. Mirhosseini M, Sharifi F, Sedaghat A (2011) Assessing the wind energy potential locations in province of Semnan in Iran. Renew Sust Energ Rev 15(1):449-459
12. Baseer $\mathrm{M}$ et al (2017) Wind power characteristics of seven data collection sites in Jubail, Saudi Arabia using Weibull parameters. Renew Energy 102: 35-49

13. Dahmouni A et al (2011) Assessment of wind energy potential and optimal electricity generation in Borj-Cedria. Tunisia Renewable and Sustainable Energy Reviews 15(1):815-820

14. Li M, Li X (2005) Investigation of wind characteristics and assessment of wind energy potential for Waterloo region, Canada. Energy Convers Manag 46(18):3014-3033

15. Lashin A, Shata A (2012) An analysis of wind power potential in Port Said, Egypt. Renew Sust Energ Rev 16(9):6660-6667

16. Himri $Y$ et al (2012) Wind energy for rural areas of Algeria. Renew Sust Energ Rev 16(5):2381-2385

17. Đurišić Ž, Mikulović J (2012) Assessment of the wind energy resource in the South Banat region, Serbia. Renew Sust Energ Rev 16(5):3014-3023

18. Ouarda T et al (2015) Probability distributions of wind speed in the UAE. Energy Convers Manag 93:414-434

19. Rehman S, Al-Abbadi NM (2005) Wind shear coefficients and their effect on energy production. Energy Convers Manag 46(15):2578-2591

20. Rehman S, Al-Abbadi NM (2008) Wind shear coefficient, turbulence intensity and wind power potential assessment for Dhulom, Saudi Arabia. Renew Energy 33(12):2653-2660

21. Fırtın E, Güler Ö, Akdağ SA (2011) Investigation of wind shear coefficients and their effect on electrical energy generation. Appl Energy 88(11):4097-4105

22. Shen X, Zhu X, Du Z (2011) Wind turbine aerodynamics and loads control in wind shear flow. Energy 36(3):1424-1434

23. Al-Abbadi NM (2005) Wind energy resource assessment for five locations in Saudi Arabia. Renew Energy 30(10):1489-1499

24. Rehman S et al (2012) Wind speed characteristics and resource assessment using Weibull parameters. Int I Green Energy 9(8):800-814

25. Bassyouni $\mathrm{M}$ et al (2015) Assessment and analysis of wind power resource using Weibull parameters. Energy Explor Exploit 33(1):105-122

26. Katinas $V$ et al (2017) Statistical analysis of wind characteristics based on Weibull methods for estimation of power generation in Lithuania. Renew Energy 113:190-201. https://doi.org/10.1016/..renene.2017.05.071.

27. Manwell JF, McGowan JG, Rogers AL (2010) Wind energy explained: theory, design and application. John Wiley \& Sons. Chichester, UK. doi:10.1002/9781119994367.

28. Akpinar EK, Akpinar S (2005) An assessment on seasonal analysis of wind energy characteristics and wind turbine characteristics. Energy Convers Manag 46(11):1848-1867

29. Amirinia G, Mafi S, Mazaheri S (2017) Offshore wind resource assessment of Persian Gulf using uncertainty analysis and GIS. Renew Energy 113:915-929

30. Yaniktepe B, Koroglu T, Savrun M (2013) Investigation of wind characteristics and wind energy potential in Osmaniye. Turkey Renewable and Sustainable Energy Reviews 21:703-711

31. Gökçek M, Bayülken A, Bekdemir \$ (2007) Investigation of wind characteristics and wind energy potential in Kirklareli, Turkey. Renew Energy 32(10):1739-1752

32. Penchah MM, Malakooti H, Satkin M (2017) Evaluation of planetary boundary layer simulations for wind resource study in east of Iran. Renew Energy 111:1-10

33. Ucar A, Balo F (2009) Evaluation of wind energy potential and electricity generation at six locations in Turkey. Appl Energy 86(10):1864-1872

34. Akdağ SA, Dinler A (2009) A new method to estimate Weibull parameters for wind energy applications. Energy Convers Manag 50(7):1761-1766

35. Chang TP (2011) Performance comparison of six numerical methods in estimating Weibull parameters for wind energy application. Appl Energy 88(1):272-282

36. Rocha PAC et al (2012) Comparison of seven numerical methods for determining Weibull parameters for wind energy generation in the northeast region of Brazil. Appl Energy 89(1):395-400

37. Ullah I, Chipperfield AJ (2010) An evaluation of wind energy potential at Kati Bandar, Pakistan. Renew Sust Energ Rev 14(2):856-861

38. Association, D.W.T.M (1999) Guided tour on wind energy. Danish Wind Turbine Manufacturers Association 